http://jmscr.igmpublication.org/home/

ISSN (e)-2347-176x ISSN (p) 2455-0450

crossref DOI: https://dx.doi.org/10.18535/jmscr/v7i7.140

Journal Of Medical Science And Clinical Research

\title{
Effect of Pranayama and "OM" meditation on visual reaction time, hand grip dynamometer endurance and stress in medical students
}

\author{
Authors \\ Dr Kavita Singh" ${ }^{*}$, Dr Rinku Garg², Dr Y. Tripathi ${ }^{3}$, Dr Navpreet Mann ${ }^{4}$ \\ Dr Vivek Sharma ${ }^{5}$ \\ ${ }^{1}$ Tutor, GIMS, Greater Noida \\ ${ }^{2}$ Professor, Dept. of Physiology, Santosh Medical College, Ghaziabad \\ ${ }^{3}$ Professor, Dept. of Physiology, Santosh Medical College, Ghaziabad \\ ${ }^{4}$ Assistant Professor, Dept of Physiology, Santosh Medical College, Ghaziabad \\ ${ }^{5}$ Professor, Dept. of Physiology, Government Institute of Medical Sciences, Greater Noida \\ Corresponding Author \\ Dr Kavita Singh \\ Tutor, GIMS, Greater Noida, India
}

\begin{abstract}
Yoga is a lifestyle which when practised gives a sense of well-being, positive attitude, calmness and serenity to mind. The benefits of Yoga can be studied by different parameters. In this study Visual reaction time, hand grip dynamomter endurance time and stress levels were measured to study the efficacy of yoga. The aim of this study was to study the benefits of yoga on medical students as they are under constant pressure to perform well. And Yoga can prove to be an inexpensive, valuable source of attaining a healthy mind and body. Yoga in the form of pranayama and meditation was performed for 15 days daily by thirty medical students of Santosh Medical College, Ghaziabad. The visual reaction time was measured by a online reaction test. HGDE was measured with the help of Hand grip dynamometer. Stress levels were assessed by STAI-A Form Y-1. The readings were taken before yoga and after yoga. Statistical analysis was done using paired t- test. We observed that VRT and stress score reduced significantly and endurance time increased significantly after performing yoga. ( $p$ value $<0.001$ ).
\end{abstract}

\section{Introduction}

Yoga is set of principles which when practised promotes health and well -being through the integration of body, breath, and mind ${ }^{1}$. It is selfempowering and helps in healing process. ${ }^{2}$ The healing comes from within and when an individual is in positive state of mind healing is quick as compared to the negative state of mind ${ }^{2}$. The voluntary rhythmic regulation of breathing to calm the mind is called Pranayama. ${ }^{3}$ According to yoga, pranayama consists of various ways of inhaling, exhaling and retention of 'prana' or breath. Pranayama have been demonstrated to produce various physiological benefits. ${ }^{(4,5)}$ Regular practice of breathing exercises (pranayama) increases parasympathetic tone, decreases sympathetic activity, improves cardio-vascular and respiratory functions, decreases the effect of stress and strain on the body and improves physical and mental health. ${ }^{6}$ Meditation is a conscious mental process that brings physiological changes in the form of 
relaxation response. The regulation of attention is a central feature of different methods of meditation $^{7}$.

Stress is defined as state of threatened homeostasis which is re-established by a complex collection of physiological and behavioural adaptive response of the individual ${ }^{8}$. Stress is a series of physiological, neurohormonal and psychological efforts to adapt to any situation that will disturb the homeostatic balance of the body $\left({ }^{9},{ }^{10}\right)$. In the competitive world of medical education, students are exposed to various stress factors like fear of failure, low scores in exams, pressure from parents to perform well. These all factors can prevent students from performing to their full calibre." The students find the medical curriculum stressful which had been shown in many physiological studies. ${ }^{12}$

Cognitive reactions of stress result in the inability to concentrate and hamper students performance. ${ }^{13}$ The sympatho-adrenal system and the hypothalamic-pitutiary-adrenal (HPA) axis may mediate the adverse effects of stress on cognitive performance. $^{(14,15,16,17)}$

Reaction time is the time interval between the application of stimulus and the appearance of voluntary response by the subject ${ }^{18}$. Reaction time measurement gives an indirect index of processing capability of CNS. It has both physiological and clinical significance, as shorter reaction time means better performance ${ }^{19}$ Meditation and other forms of yoga and breathing techniques cause a decrease in the reaction time of the subjects ${ }^{20}$.

Hand grip endurance is used as an indicator for muscle function. $^{21}$

\section{Material and Methods}

This study was conducted on 30 healthy medical students (boys and girls) between the age group of 18-25 years. The students were randomly selected by simple random sampling method, at SANTOSH MEDICAL COLLEGE, Ghaziabad. Detailed explanation of the study was given to the students and informed consent was taken. The study was approved by the ethical committee of the institute.

\section{Inclusion Criteria}

- Healthy medical students in the age group of 18-25 years.

\section{Exclusion Criteria}

- Subjects with any acute illness.

- Subjects with history of Asthma, Tuberculosis, Cataract, Diabetes Mellitus, Hypertension or any other Cardio Vascular disease.

- Subjects with colour blindness or sensorymotor disability.

- Subjects with any muscular disorder.

- Subjects taking any anti-psychotic treatment.

For assessment of STAI-A: Spielberger's state trait anxiety inventory for adults (STAI-A) Form Y-1 questionnaire was used. It has 20 questions with four possible options. The final score was calculated by the answer key provided with the questionnaire. . They were asked not to spend much time on one question. It uses a 4-point Likert scale to allow the subject to show how often or how much each question applies to them in a situation ${ }^{47}$. The students filled the questionnaire twice i.e before and after yoga.

Visual Reaction Time: Online reaction test was used $^{22}$ for measuring the visual reaction time. The students were demonstrated how the test was to be performed. The student was seated comfortably on the chair in front of the computer screen. The students were asked to click on the button as quickly as possible when the colour changed from red to green with their dominant hand. Three readings were taken and average was considered. The VRT was assessed twice, before and after yoga.

Hand Grip Dynamometer Endurance: Hand grip dynamometer was used. The students were explained and demonstrated the procedure. The student was seated comfortably on a chair with forearm resting on the table. The student was asked to hold the dynamometer and pull the handle and maximum voluntary contraction was recorded $^{23}$. The student was asked to pull the grip 
with $80 \%$ of maximum voluntary contraction and duration of time they were able to hold gave the endurance time in seconds. Endurance time was recorded with the help of stop watch. Same instrument was used for all the students.

YOGA: The yoga technique was taught and demonstrated by an instructor in Department of Physiology, SANTOSH MEDCIAL COLLEGE, GHAZIABAD.

Pranayama (Brahmari and anulom-vilom) and meditation was done for $25 \mathrm{~min}$ in morning for 15 days. Students were asked to come empty stomach in the morning at 8:00 am.

Anulom-vilom: The students were made comfortable and were instructed to sit straight in 'padmasana' and keep the spine straight. The students were then asked to close one nostril (say left) by his/her thumb and slowly breathe in with right nostril. Then close the right nostril with ring finger and exhale through the left nostril. They were then asked to keep the right nostril closed, inhale slowly through the left nostril. Then close the left nostril and exhale through the right nostril. This completed one cycle of anulom-vilom. ${ }^{24}$ Such cycles was repeated for $5 \mathrm{~min}$.

Bhramari pranayama: The students were made comfortable and were instructed to sit straight in 'padmasana' and keep the spine straight. They were told to put the thumb of left and right hand over the tragus of respective ears. Eyes closed and the index finger of each hand were placed on the outer corners of the eyelids, the middle finger on the side of the nose near the nostrils, fourth finger above the little finger below the corners of the mouth. Now the students were asked to breath from both the nostrils and focus in between the eyelids and imitate the sound of buzzing bee while exhaling through the nasal cavity keeping the mouth closed. ${ }^{25}$ This was repeated for $5 \mathrm{~min}$. There after normal breathing for $5 \mathrm{~min}$. followed by meditation.

Meditation: In the "padmasana" posture, students were asked to close their eyes and breathe naturally and focus their attention on their breathing. "OM" sound was played on tape recorder. The students were asked to focus on their breath and repeat ' $O M$ ' in the following manner ${ }^{26}$ : Exhale: "OMmmmmmmm..." Inhale: "OMmmmmmmm..."

Exhale: "OMmmmmmmm..." Inhale: "OMmmmmmmm..." Meditation was done for 10 $\min$.

Statistical analysis: The data collected was analysed by SPSS version 18. Mean and standard deviation was calculated. The paired t- test was used and $\mathrm{p}$ value $<0.05$ was considered as significant.

\section{Result}

Thirty students were enrolled for this study and conducted in department of physiology in Santosh Medical College, Ghaziabad.

Table 1: Demographic Profile of the MBBS Students Studied

\begin{tabular}{|l|c|c|}
\hline Variables & Number & Cases \\
\hline Mean age (in years) & 30 & $19.4 \pm 1.1$ \\
\hline Age Range & 30 & 17 to 22 years \\
\hline Mean weight $(\mathrm{kg})$ & 30 & $61 \pm 11$ \\
\hline Weight range & 30 & 42 to $80 \mathrm{~kg}$ \\
\hline Mean height $(\mathrm{cm})$ & 30 & $163.9 \pm 10.3$ \\
\hline Height range & 30 & 140 to $180 \mathrm{~cm}$ \\
\hline Sex ratio $(\mathrm{M}: \mathrm{F})$ & 30 & $13: 17$ \\
\hline
\end{tabular}

Table 2: Comparison of physiological parameters Pre Yoga and Post Yoga.

\begin{tabular}{|c|c|c|c|c|c|}
\hline & \multicolumn{3}{|c|}{ Cases } & \multirow{2}{*}{$\begin{array}{c}\mathrm{T} \\
\text { value }\end{array}$} & \multirow{2}{*}{$\begin{array}{c}\mathrm{P}^{*} \\
\text { value }\end{array}$} \\
\hline & Number & $\begin{array}{l}\text { Pre } \\
\text { Yoga }\end{array}$ & $\begin{array}{l}\text { Post } \\
\text { Yoga }\end{array}$ & & \\
\hline $\begin{array}{l}\text { VRT (m } \\
\text { seconds) }\end{array}$ & 30 & $\begin{array}{c}695.1 \\
\pm 142.3\end{array}$ & $\begin{array}{c}407.9 \\
\pm 88\end{array}$ & 13.623 & 0.001 \\
\hline $\begin{array}{l}\text { HGE } \\
\text { (seconds) }\end{array}$ & 30 & $\begin{array}{c}74.6 \pm \\
39.3\end{array}$ & $\begin{array}{r}102.2 \\
\pm 41.2\end{array}$ & $\begin{array}{c}- \\
10.546\end{array}$ & 0.001 \\
\hline $\begin{array}{l}\text { STAI } \\
\text { score }\end{array}$ & 30 & $\begin{array}{c}42.5 \pm \\
9.6\end{array}$ & $\begin{array}{c}34.6 \pm \\
6.8\end{array}$ & 11.017 & 0.001 \\
\hline
\end{tabular}

*Paired $t$ test

The above table shows that there was decrease in the VRT and STAI score after 15 days of yoga practice \& the difference is significant statistically. On the other hand, the value of HGDE after 15 days of yoga practice has increased and this difference is significant statistically.

\section{Discussion}


In this study we observed that following yoga for fifteen days, there was significant decrease in VRT $(\mathrm{p}<.001)$, significant decrease in STAI-A score $(p<0.001)$ and significant increase in HGDE $(p<0.001)$. The significant reduction in visual reaction time was consistent with the findings of study which showed a reduction in reaction time following three weeks of yoga training in slow and fast pranayama. ${ }^{27}$ The present study results were also similar to the study conducted on female medical students which demonstrated that effects of yoga practice start immediately and these effects are marked and significant on visual reaction time, STAI-A score, auditory reaction time, sense of well-being except hand grip dynamometer endurance. ${ }^{28,29}$ Similar results have been reported by a study done on male healthy volunteers. ${ }^{30}$ The decrease in visual reaction time after pranayama may be due to regulation of activity at ascending reticular activating system and alteration in processing of information at the primary thalamo-cortical level occurring during pranayama. ${ }^{(27,32)}$ Decrease in VRT suggests improvement in sensory motor performance and processing ability after Bhastrika pranayama and Anulom-Vilom. ${ }^{(24,33)}$ The practice of pranayama involves focussing one's attention on breathing and so yoga may boost general attention abilities ${ }^{34}$. This may be the reason of decrease in VRT after yoga. The visual reaction time may be used as a simple and effective method to determine the beneficial effects of yoga ${ }^{(5,35)}$. The study reported that 'OM' chanting has beneficial \& significant effects on perceived stress, auditory and visual reaction time in female school teachers and thus concluded that "OM" mantra if practised regularly improves the quality of life and relives stress. ${ }^{36}$ The decrease in visual reaction time is seen after breathing techniques as well as meditation ${ }^{37} \&$ so the reduced visual reaction time in the present study may be due to the combined conducive effects of pranayama \& meditation.

Our observations are also in agreement with the studies which reported that yoga exercise produces a significant increase in muscle endurance time ${ }^{(38,39,40)}$ and also noted delay in the onset of fatigue. ${ }^{41}$ The rise in hand grip dynamometer endurance values can be explained by the improvement in autonomic tone which causes increased parasympathetic drive, calming of stress responses, neuro-endocrine release of hormones and thalamic generators ${ }^{42}$. Improved autonomic tone in pranayama practice reduces oxygen requirement and as it is known that availability of energy and oxidation of glucose influence the hand grip strength ${ }^{30}$ and hand grip endurance.

The positive effects of yoga on stress reduction in college students similar to the present study had been shown by many studies. ${ }^{43}$ A similar study on effect of short-term yoga practice reported a reduction in state and trait anxiety scores in healthy subjects as well as patients after 10 days of yoga intervention program \& suggested that even short-term yoga program can lead to reduction in stress and anxiety in the individuals ${ }^{44}$. Another study done on medical and paramedical students revealed that three days of meditation training was effective in reducing pain, sensitivity and anxiety scores. Meditation techniques have been used to regulate the mind, emotions, and the responses in adverse psychological conditions. ${ }^{45}$

Chanting 'OM' mantra results in stabilization of brain, removal of worldly thoughts and increase of energy, creativity and performance at workplace. It also brings certainty in mind, increases selfawareness, being open for positive thoughts and simultaneously disrupts negative thoughts that heals the body on a cellular level, with more energy, strength and focus. ${ }^{(36,46)}$

\section{Conclusion}

Yoga reduced the visual reaction time and STAIA score \& increased the hand grip dynamometer endurance. The yoga causes sympatho-vagal balance and thus Pranayama and meditation relaxes the mind \& body. Teaching yoga to medical students can decrease mental distress and increase their well- being. In the present study 
only 25 minutes of yoga practice for 15 days resulted in its benefits. Thus, if yoga can be practised daily as a routine it may impart positive effects and improve the life style of the students and prepare them for their upcoming life.

\section{Acknowledgment}

We would like to thank the students of our college for their support and cooperation.

\section{References}

1. Meg Hayes, Sam Chase -Prescribing Yoga, Prim. Care. Mar.2010; 37(1): 3236

2. Woodyard C. Exploring the therapeutic effects of Yoga and its ability to increase quality of life. Int. J. Yoga 2011; 4: 49-54.

3. Telles, Nagarathna And Nagendra. Breathing through a particular nostril can alter metabolism and autonomic activities. IJVPP 1994; 38(2): 133-137.

4. Madan Mohan, Jatiya L, Udupa R, Bhavnani AB. Effects of Yoga training on Hand grip, respiratory pressures and pulmonary function. IJJP 2003; 47(4): 387-92.

5. Malathi A, Parulkar UG. Effects of Yogasanas on the visual and auditory reaction time. Indian J. PhysiolPharmacol. 1989; 33-110-112

6. Raju PS, Madhavi S, Prasad KV. Comparison of effects of Yoga and Physical exercises in athletes. Indian $\mathrm{J}$ Med. Res. 1994; 100-81-86

7. Davidson RJ, Goleman DJ. The role of attention in meditation and hypnosis: A psychobiological perspective on transformations of consciousness. Int $\mathrm{J}$ Clin Exp Hypn. 1977;25(4):291-30

8. Chrousos GP. Stress and disorders of the Stress system. Nat. Rev Endocrine.2009 Jul; 5(7): 379-81

9. Chrousus GP. Stress as a medical and scientific idea and its implications.
Advances in Pharmacology; 1997; 42: 522-556.

10. Froehlich WD, Stress, anxiety and control of attention: A psycho-physiological approach in C.D Spielberg and I.G Sarason (Eds): Stress and anxiety, Washington DC. Vol 5:99-130

11. Wadikar SS, Muley PA, Muley PP. Effect of exam stress on reaction time in medical students2014; 15: 24-80

12. Mamoza M. A. Stress and depression among medical students: A cross sectional study at a medical college in Saudi Arabia. Pak J Med Sci 2008; G24(1):12-17

13. Sailer HS, Schlacter J, Edwards MR. Stress- causes, consequences and coping strategies. Personal 1982; 59: 35-48.

14. Valentino RJ, Van Bockstale E. Convergent regulation of locus coeruleus activity as an adaptive response to stress. Eur J Pharmacol. 2008; 583(2-3): 194-203

15. Sara SJ. The locus coeruleus and noradrenergic modulation of cognition. Nat Rev Neurosci. 2009;10(3): 211-223

16. Lupien SJ, Lepage M. Stress, memory, and the hippocampus: can't live with it, can't live without it. Behav Brain Res.2001; 127(1-2): 137-158

17. McEwen BS. Physiology and Neurobiology of Stress and adaptation: central role of brain. Physiol Rev. 2007; 87(3): 873-904

18. Mohan M, Thombre DP, Das AK, Subramanian N, Chandrashekhar. Reaction time in clinical Diabetes Mellitus. Ind J. Physiol. Pharmacol 1984; 28: 311-314

19. Tandon OP, The average evoked potentialThe clinical application of the short latency response. Indian J Physio Pharma 1998; 42(2): 172-80.

20. Bharati Rajak, Dr. Rajeev Choudhary. Effect of Sahaja Yog meditation and pranadharna on reaction time of university female students. International Journal of Applied Research 2016; 2: 1025-1028 
21. Venkatesh R Rathod, Manoj T Jiwtode. Effect of 4 months yoga training on hand grip strength and hand grip endurance in children in Nagpur. Int. J Med Sci Public Health 2016; 5: 2209-2211

22. The online reaction time test http://getyourwebsitehere.com/jswb/rttest0 1.html

23. Garg, R., Malhotra, V., Kumar, A., Dhar, U., \& Tripathi, Y. Effect of isometric handgrip exercise training on resting blood pressure in normal healthy adults. Journal of clinical and diagnostic research. JCDR 2014; 8(9): BC08-10.

24. Bamne SN. Immediate effect of anulomvilom pranayama on reaction time of 18 20 years of age groups. Natural journal of Physiology, Pharmacoloy, Pharmacy. 2017;7(8): 812-814

25. P. Rajkishor, M. Fumitoshi, H. Bakardjia, F. Vialatte, A. Cichocki EEG changes after Bhramari Pranayama Paper Presented at: SCIS \& ISIS (2006)

26. Ajay Anil Gurjar, Siddharth A. Ladhake, Ajay P. Thakare. Analysis of Acoustic of "OM" Chant To Study It's Effect on Nervous system. IJCSNS 2009; 9(1): 363367

27. Dr. S.B. Jore1, Dr.PrathameshKamble , Dr. T.B. Bhutada, Dr. M.S. Patwardhan. Effect of Pranayama training on AudioVisual Reaction Time International J. of Healthcare \& Biomedical Research. 2013; 2(1): $35-37$

28. Madanmohan, Thombre DP, Balakumar B, Nambinarayanan TK, Thakur S, Krishnamurthy $\mathrm{N}$, et al. Effect of yoga training on reaction time, respiratory endurance and muscle strength. Indian $\mathbf{J}$ Physiol-Pharmacol. 1992; 36:229-33

29. Madanmohan, Thombre DP, Balakumar B, Nambinarayanan TK, Thakur S, Krishnamurthy $\mathrm{N}$, et al. Effect of yoga training on reaction time, respiratory endurance and muscle strength. Indian $\mathbf{J}$ Physiol-Pharmacol. 1992; 36:229-33

30. Mohinder P, Malik SL. Effect of smoking on anthropometric somatotype and grip strength. Indian J Med Res. 1988; 87: 49499.

31. Dr. S.B. Jore1, Dr.PrathameshKamble , Dr. T.B. Bhutada, Dr. M.S. Patwardhan. Effect of Pranayama training on AudioVisual Reaction Time International J. of Healthcare \& Biomedical Research. 2013; 2(1): 35-37

32. Bhavnani AB, Ramanathan M, Hari chandrakumar RT. Immediate effect of mukhBhastrika on reaction time in mentally challenged adoloscents. Indian J. PhysiolPharmacol 2012; 56: 174-80

33. Shashikala GV, Shashidhara PK, Baljoshi VS. Effect of mukhBhastrika (a type of pranayama) on sensory-motor performance. Journal of clinical and diagnostic research 2011; 5(5): 1034-1037

34. Sheela joice PP, Gunasekharan R. Influence of yoga on audio-visual reaction time of medical students. JMSCR 2015; 3(11): 8162-8166.

35. Naveen KV, Nagendra HR, Nagarathana $\mathrm{R}$, Telles S. Breathing through a particular nostril improves spatial memory scores without lateralized effects. Psychol Res 1997; 81: 555- 561

36. Mishra, Soumya \& Rajagopalan, Archana \&Goothy, Sai Sailesh\&Bashetti, Srilatha \& Ashok, Swathy\& Kumar Reddy, Udaya \& J Antony, N \& Joy, Ayana \&Jk, Mukkadan. Beneficial effects of OM chanting on perceived stress, auditory and visual reaction time in private school teachers. International Journal of Research in Ayurveda \& Pharmacy. 2017; 8. 79-81.

37. Saraswati SS (2002) Meditation from the tantras. Yoga publication trust, Bihar.

38. Raghuraj P, Telles S. Muscle power, dexterity skill and visual perception in community home girls trained in yoga or 
sports and in regular school girls. Indian J PhysiolPharmacol 1997; 41:409-415

39. Thirupathi C, Aanandha Subramaniam K. Effect of Yogasana and Pranayama on weight, muscle strength and endurance in young Male Medical Students 2017; 6 (1): $1-3$

40. Thangavel, Dinesh \& Sharma, Vivek \& Singh Gaur, Girwar\&Bhavanani, Ananda \&Manivel, Rajajeyakumar\& Kiran Ph D, A N Syam. Effect of Slow and Fast Pranayama training on Handgrip Strength and Endurance in Healthy Volunteers. Journal of Clinical and Diagnostic Research.2014; 8: 01-03

41. Shah C. et al. Common stressors and coping of stress by medical students. Journal of Clinical and Diagnostic Research. August 2009; 3(4): 1621-1626

42. Ray US, Mukhopadhyaya S, Purkayastha SS et al. Effect of yogic exercises on physical and mental health of young fellowship course trainees. Indian $\mathbf{J}$ Physiol Pharmacol 2001; 45 (1): 37-53

43. Malathi A, Damodaran A. Stress dur to exams in medical students- Role of yoga. Indian J. Physiol. Pharmacol. 1999 Apr; 43(2): 218-24

44. Bhavanani, Ananda \& Ramanathan, Meena \& Dayanidy, Ganesan \& Trakroo, Madanmohan K, Renuka. A Comparative Study of the Differential Effects of Shortterm Asana and Pranayama Training on Reaction Time. Annals of Medical and Health Sciences Research. 2017; (7): 8083

45. Shapiro SL, Schwartz GE, Bonner G. Effects of mindfulness-based stress reduction on medical and premedical students. J Behav Med 1998;21: 581-99.

46. Manish Kumar Dwivedi and Prof S. K. Singh, "Scientific analysis of Aum mantra in knowing Self" https:// www.researchgate.net/ 312153393

47. Spielberger CD, Gorusch RL, Lushene RE. STAI-A Manual for State -Trait Anxiety Inventory. Palo Alto, CA: Consulting Psychologists Press, 1970. 
